NASA/TM-1999-208905

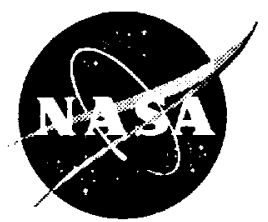

\title{
Surface Design and Engineering Toward Wear-Resistant, Self-Lubricating Diamond Films and Coatings
}

Kazuhisa Miyoshi

Lewis Research Center, Cleveland, Ohio

Prepared for the

128th Annual Meeting \& Exhibition

sponsored by The Minerals, Metals \& Materials Society

San Diego, California, February 28-March 4, 1999

National Aeronautics and

Space Administration

Lewis Research Center 


\section{Acknowledgments}

The author thanks Dr. R.L.C. Wu and his group at the Air Force Research Laboratory for depositing the microwave-plasma-enhanced CVD diamond films used for disk specimens and the ion-beam-deposited DLC films and Professor Murakawa and his group at the Nippon Institute of Technology for depositing the cubic boron nitride films and the hot-filament CVD diamond films used for pin specimens.

Available from

NASA Center for Aerospace Information

National Technical Information Service

7121 Standard Drive

Hanover, MD 21076

5285 Port Royal Road

Springfield, VA 22100

Price Code: A03

Price Code: A03 


\title{
SURFACE DESIGN AND ENGINEERING TOWARD WEAR-RESISTANT, SELF-LUBRICATING DIAMOND FILMS AND COATINGS
}

\author{
Kazuhisa Miyoshi \\ National Aeronautics and Space Administration \\ Lewis Research Center \\ Cleveland, Ohio 44135
}

\begin{abstract}
The tribological properties of chemical-vapor-deposited (CVD) diamond films vary with the environment, possessing a Jekyll-and-Hyde character. CVD diamond has a low coefficient of friction and high wear resistance in air but a high coefficient of friction and low wear resistance in vacuum. Improving the tribological functionality of diamond films (such as achieving low friction and good wear resistance) was the ultimate goal of this investigation.

Three studies on the surface design, surface engineering, and tribology of CVD diamond have shown that its normally high friction and wear in ultrahigh vacuum can be significantly reduced. The main criteria for judging whether diamond films are an effective wear-resistant, self-lubricating material were coefficient of friction and wear rate, which must be less than 0.1 and on the order of $10^{-6} \mathrm{~mm}^{3} / \mathrm{N} \cdot \mathrm{m}$, respectively. In the first study, the presence of a thin film $(<1 \mu \mathrm{m}$ thick) of amorphous, nondiamond carbon (hydrogenated carbon, also called diamondlike carbon or DLC) on CVD diamond greatly decreased the coefficient of friction and the wear rate. Therefore, a thin DLC film on CVD diamond can be an effective wear-resistant, lubricating coating in ultrahigh vacuum. In the second study the presence of an amorphous, nondiamond carbon surface layer formed on CVD diamond by ion implantation significantly reduced the coefficient of friction and the wear rate in ultrahigh vacuum. Therefore, such surface layers are acceptable for effective selflubricating, wear-resistant applications of CVD diamond. In the third study CVD diamond in contact with cubic boron nitride exhibited low coefficient of friction in ultrahigh vacuum. Therefore, this materials combination can provide an effective self-lubricating, wear-resistant couple in ultrahigh vacuum.
\end{abstract}

\section{Introduction}

High tribological reliability is of crucial importance in operating the many interacting surfaces that are in relative motion in mechanical systems (1). The goals of tribological research and development are to reduce the adhesion, friction, and wear of mechanical components; to prevent their failure; and to provide long, reliable component life through the judicious selection of materials, coatings, surface modifications and treatments, operating parameters, and lubricants.

A notable amount of research effort has been put into fundamental studies of the tribological behavior of coatings. In recent years, the increasing potential for the use of diamond films and 
diamondlike films as tribological coatings in mechanical systems such as bearings, seals, and gears has focused attention on these coating materials (2). Tribological studies have been conducted with diamond and related coatings to understand better how the physical and chemical properties of these coatings will affect their behavior when in contact with themselves, ceramics, polymers, and metals (3-5).

Three surface design, surface engineering, and tribology studies have shown that the normally high friction and wear of CVD diamond in ultrahigh vacuum can be significantly reduced. This paper discusses the results of those studies: first, the friction mechanisms of clean diamond surfaces; second, the solid lubrication mechanism and the surface design of diamond surfaces; and finally, the actual tribological properties of the modified diamond surfaces and the selected materials couple. How surface modification and the selected materials couple (particularly the diamond-cubic boron nitride couple) improved the tribological functionality of coatings, giving low coefficient of friction and good wear resistance, is explained.

\section{Friction Mechanism of Diamond Surface}

\section{General Friction Mechanism}

The classical Bowden and Tabor model for sliding friction $(6,7)$, in its simple form, assumes that the friction force arises from two contributing sources. First, an adhesion force is developed at the real area of contact between the surfaces (the asperity junction). Second, a deformation force is needed to plow or cut the asperities of the harder surface through the softer. The resultant friction force is the sum of the two contributing sources: friction due to adhesion and friction due to deformation and/or fracture (6). The adhesion arises from the attractive forces between the surfaces in contact. This model serves as a starting point for understanding how thin surface films can reduce friction and provide lubrication (8-10). It should be realized, however, that one of the contributing sources acts to affect the other on many occasions. In other words, the two sources cannot be treated as strictly independent.

When a smooth diamond flat is brought into contact with a smooth spherical surface of diamond, ceramic, metal, or polymer, the plowing or cutting contribution in friction can be neglected. The friction due to adhesion is then described by the equation (6)

$$
\mu=s A / W
$$

In this equation, $\mu$ is the coefficient of friction, $s$ is the shear strength of the real area of contact, $A$ is the real area of contact between the surfaces, and $W$ is the load. Also, in such a basic contact condition, if we consider the total surface energy in the real area of contact, the coefficient of friction can be expressed as a function of $\gamma \mathrm{A}$

$$
\mu=f(\gamma A)
$$

Here $\gamma A$ is the total surface energy in the real area of contact $(11,12)$. To reduce friction and to provide lubrication, therefore, the shear strength $s$, the real area of contact $A$, and surface energy $\gamma$ must be minimized. 


\section{Specific Friction Mechanism}

Because diamond has tetrahedral, covalent bonds between each carbon atom and its four nearest neighbors, the free surface may expose dangling bonds. Such a free surface has high surface energy $\gamma$, which is associated with dangling bond formation. When an atomically clean diamond surface contacts an atomically clean surface of counterpart material, the dangling bonds can form strong linkages with bonds on the counterpart surface. Many researchers (e.g., 2, 3, 7, 13) have found that atomically clean diamond exhibits high adhesion and friction. For example, if the surfaces of natural diamond and metal are cleaned by argon ion bombardment, the coefficient of friction is higher than 0.4 in an ultra-high-vacuum environment. The coefficient of friction increases with an increase in the total surface energy of the metal in the real area of contact $\gamma A$. With the argon-sputtercleaned diamond surface there are probably dangling bonds of carbon ready to link up directly with metal atoms on the argon-sputter-cleaned metal surface. Thus, cleaning the diamond surface provided surface defects, such as dangling bonds, and accordingly high surface energy and enhanced adhesion and shear strength at the interface. The extremely high hardness and high elastic modulus of diamond provided a small real area of contact $A$. Although $A$ was small, large values of $s$ and $\gamma$ resulted in a high coefficient of friction for the argon-sputter-cleaned diamond surface in ultrahigh vacuum (Fig. 1).

The situation illustrated in Fig. 1 applies to sliding contacts of the CVD diamond surface with itself or other materials in ultrahigh vacuum $(2,6,7,9-15)$. Without sputter cleaning or heating to high temperature in a vacuum, a contaminant surface film is adsorbed on the CVD diamond surface. The contaminant surface film can be removed when it repeatedly slides over the same track of counterpart material in vacuum. Then, a fresh, clean diamond surface contacts a clean surface of counterpart material, and a strong bond forms between the two materials. As a result the coefficient of

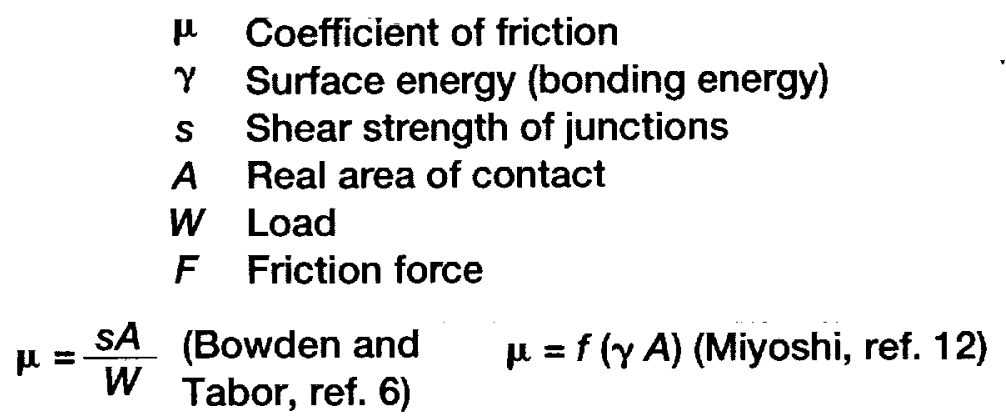

Ultrahigh vacuum

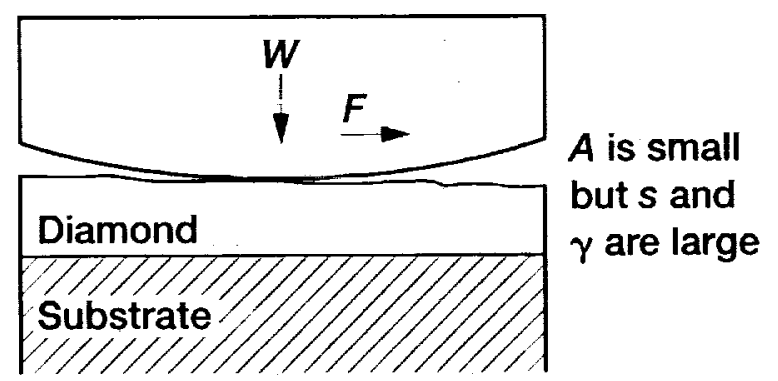

Figure 1.-Fricton mechanism of clean diamond surface in ultrahigh vacuum. 


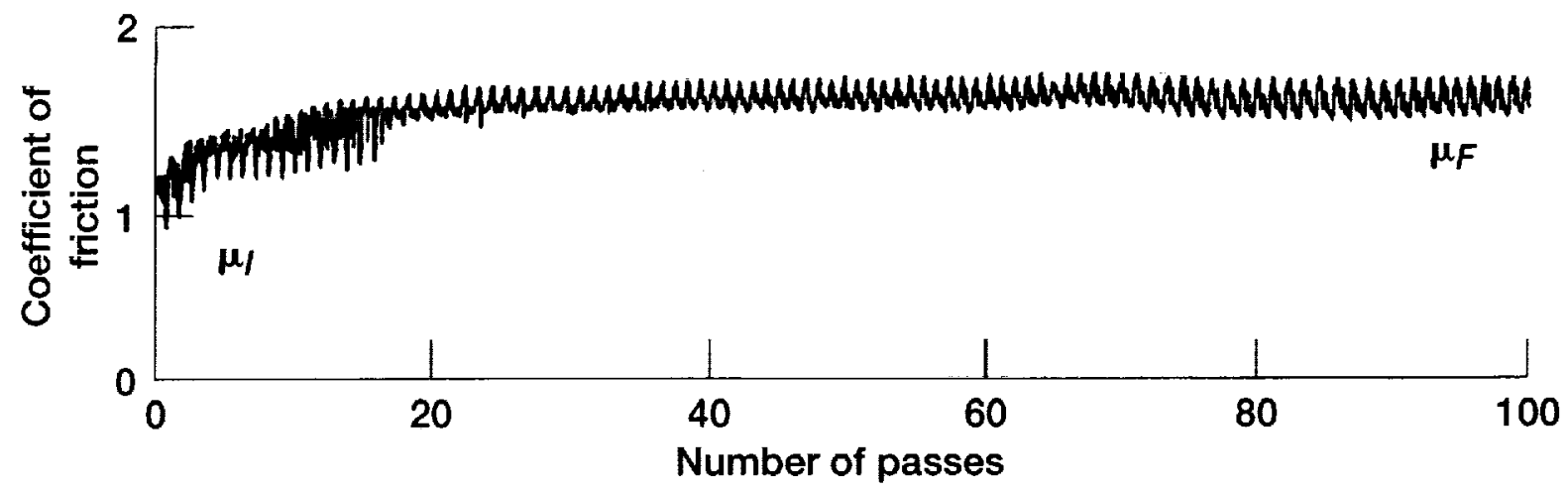

Figure 2.-Typical friction trace for bulk diamond pin in contact with diamond film deposited on $\alpha$ silicon carbide surface in vacuum $\left(\mu_{l}=\right.$ initial coefficient of friction; $\mu_{F}=$ equilibrium coefficient of friction.) Note that in humid air the initial coefficient of friction was 0.13 for fine-grain diamond films.

friction for the diamond film becomes considerably high. As shown in Fig. 2, when a contaminant surface film was removed by repeatedly sliding a diamond pin over the same track of a diamondcoated disk in vacuum, the coefficient of friction increased from the initial value $\mu_{,}$to the equilibrium value $\mu_{F}$ with an increasing number of passes. Figure 3(a) presents the initial and equilibrium coefficients of friction for a diamond pin sliding on various CVD diamond films in vacuum (13). In all cases the equilibrium coefficients of friction (1.5 to 1.8) were greater than the initial coefficients of friction (1.1 to 1.3) regardless of the initial surface roughness of the diamond films. As shown in Fig. 3(b) the wear rate of the CVD diamond films in vacuum did depend on the initial surface roughness of the films, generally increasing with an increase in the initial surface roughness.

\section{Solid Lubrication Mechanism and Design of Diamond Surface}

According to the discussion and understanding described in the previous section, reducing the coefficient of friction requires minimizing the shear strength of the interface, the surface energy, the real area of contact, and the plowing or cutting contribution. Reducing wear generally requires minimizing these factors while maximizing the hardness, strength, and toughness of interacting materials. Toward this end, surface design and engineering can be applied to reduce the coefficient of friction and wear rate of CVD diamond.

Figure 4 illustrates how the minimization of the aforementioned factors can be achieved. The introduction of a thin film overlayer, such as nondiamond carbon on diamond, reduces the coefficient of friction. In the model presented, the thin film covers the diamond. The thin film can be any material, such as soft metal, polymer, ceramic, or a modified surface layer of the diamond, that has low shear strength or low surface energy. The underlying diamond reduces both the real area of contact and the plowing contribution of the counterpart material; a thin film or a thin surface layer reduces the shear strength and surface energy in the real area of contact. The low coefficient of friction can be attributed to the combination of the low shear strength and the low surface energy of the thin film or the thin surface layer and the small real area of contact resulting from the high elastic modulus and hardness of the underlying diamond film. 

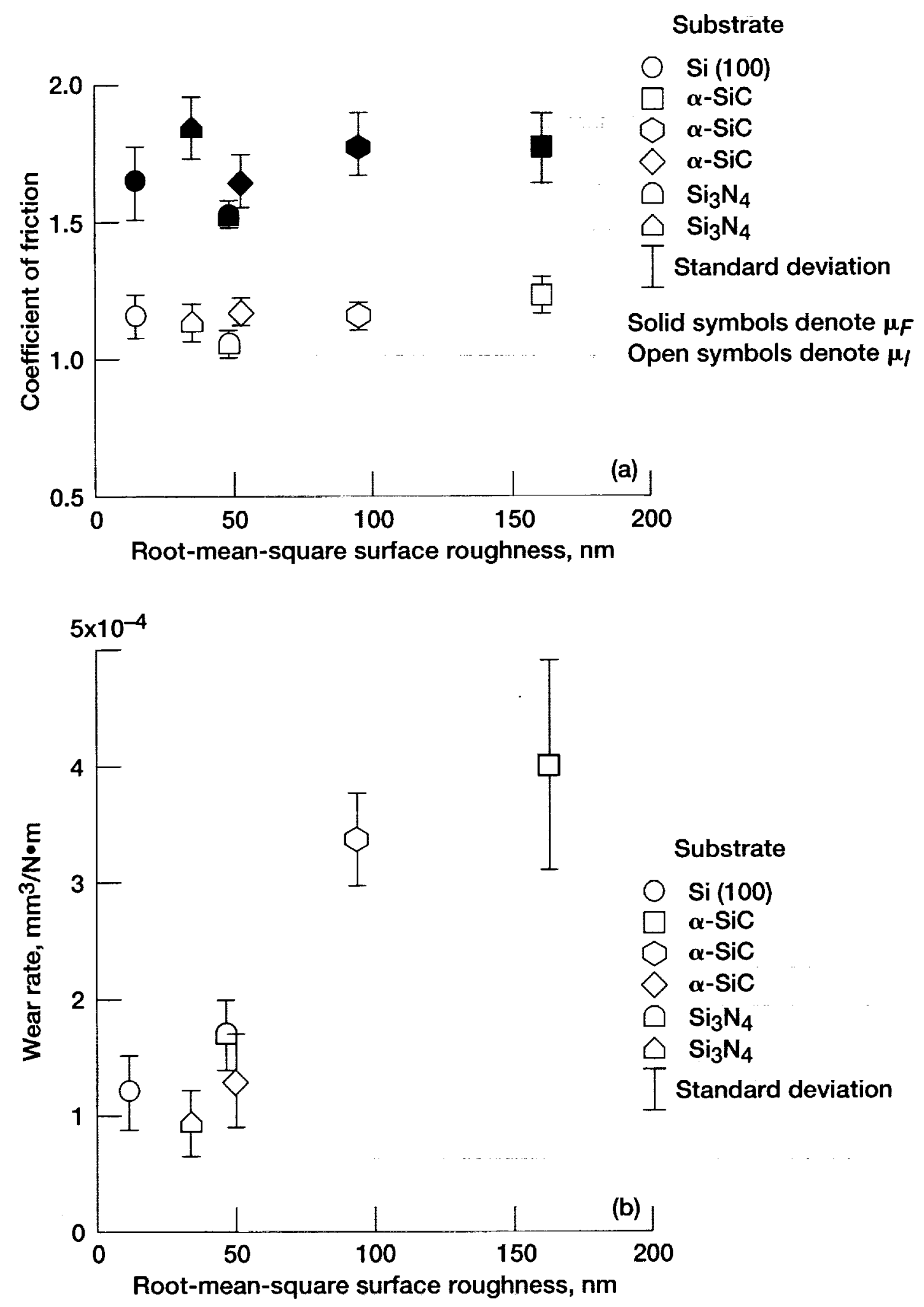

Figure 3.-Initial $\left(\mu_{l}\right)$ and equilibrium $\left(\mu_{F}\right)$ coefficients of friction and wear rates of diamond films in contact with natural diamond pin as a function of initial surface roughness of diamond film in ultrahigh vacuum. (a) Coefficient of friction. (b) Wear rate. 
$\mu$ Coefficient of friction

$\gamma$ Surface energy (bonding energy)

$s$ Shear strength of junctions

$A$ Real area of contact

$W$ Load

$F$ Friction force

$\mu=\frac{s A}{W} \underset{\text { Tabor, ref. } 6 \text { ) }}{\text { (Bowden and }}$

$\mu=f(\gamma A)$ (Miyoshi, ref. 12)

Both $s$ and $A$

are small

Both $\gamma$ and $A$

are small

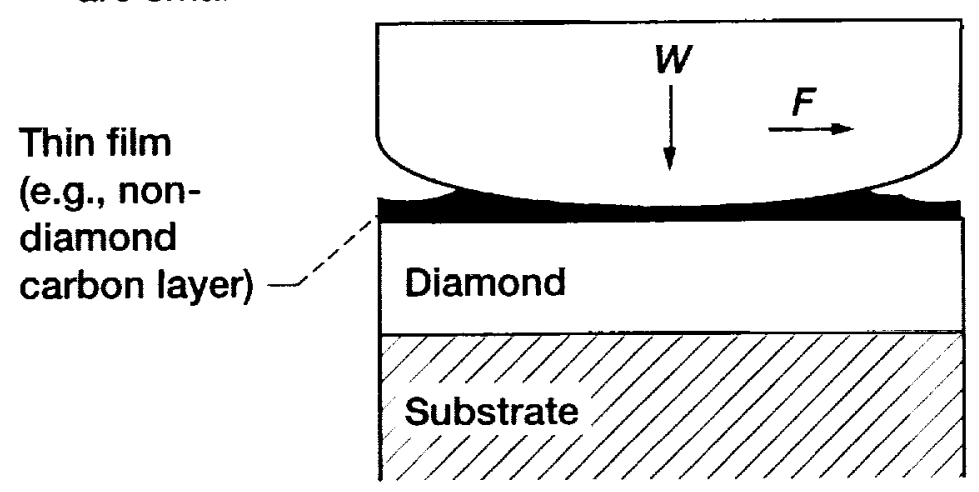

Figure 4.-Lubrication mechanisms.

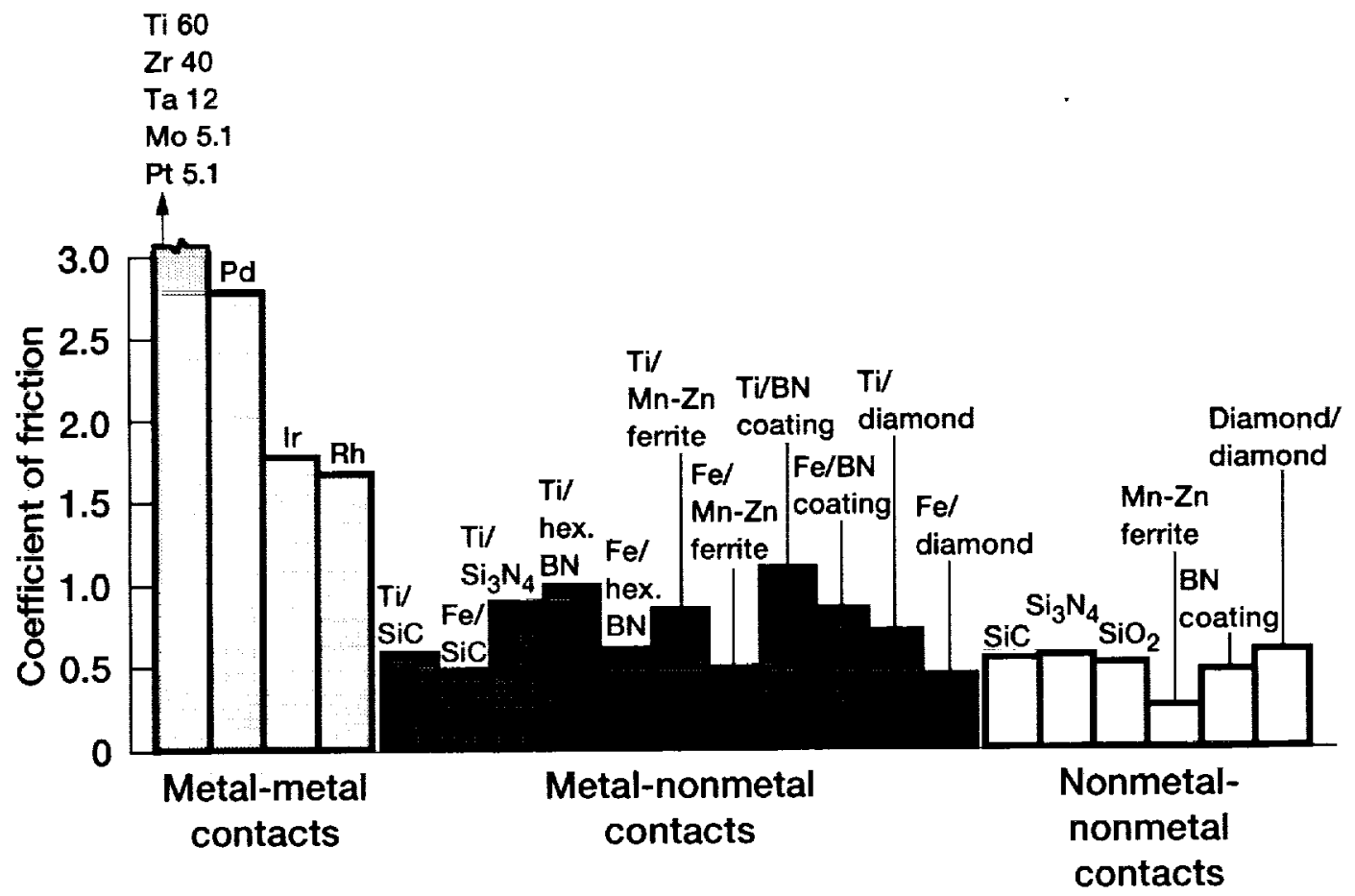

Figure 5.-Coefficient of friction for clean solid in sliding contact with itself or other material in ultrahigh vacuum. 
The coefficient of friction for clean interacting surfaces in ultrahigh vacuum also strongly depends on the materials coupled. Figure 5 presents examples of the coefficients of friction for clean metalmetal couples, clean metal-nonmetal couples, and clean nonmetal-nonmetal couples measured in ultrahigh vacuum. The judicious selection of counterpart materials can reduce the coefficient of friction of diamond in ultrahigh vacuum. The following examples show how the friction and wear of diamond films can be reduced by soft overlayers or by choice of sliding counterface material.

\section{Surface-Modified Diamond}

Figure 6 presents the steady-state (equilibrium) coefficients of friction and wear rates at room temperature in an ultrahigh vacuum $\left(10^{-7} \mathrm{~Pa}\right)$. For a direct comparison the coefficients of friction and the wear rates were plotted from $10^{-2}$ to $10^{1}$ and from $10^{-8}$ to $10^{-3} \mathrm{~mm}^{3} / \mathrm{N} \cdot \mathrm{m}$, respectively. An effective wear-resistant, self-lubricating material must generally have a coefficient of friction less than 0.1 and a wear rate on the order of $10^{-6} \mathrm{~mm}^{3} / \mathrm{N} \cdot \mathrm{m}$.

As shown in Fig. 6(a) both the as-deposited, fine-grain CVD diamond film and the polished, coarsegrain CVD diamond film had high coefficients of friction $(>0.4)$ and high wear rates (on the order of $\left.10^{-4} \mathrm{~mm}^{3} / \mathrm{N} \cdot \mathrm{m}\right)$, which are not acceptable for solid lubrication applications (13-15).

\section{Thin DLC Film on CVD Diamond}

As shown in Fig. 6(b) the thin film of DLC deposited on the as-deposited, fine-grain diamond by the direct impact of an ion beam resulted in low coefficients of friction $(<0.1)$ and low wear rates (on the order of $\left.10^{-6} \mathrm{~mm}^{3} / \mathrm{N} \cdot \mathrm{m}\right)(14-16)$. The presence of a thin $(<1 \mu \mathrm{m}$ thick), amorphous, nondiamond carbon (hydrogenated carbon) film on CVD diamond greatly decreased the coefficient of friction and the wear rate. DLC on CVD diamond can be an effective wear-resistant, lubricating coating in ultrahigh vacuum.

Note that in dry nitrogen and in humid air (not shown) the coefficient of friction was less than 0.1 and the wear rate was on the order of $10^{-6} \mathrm{~mm}^{3} / \mathrm{N} \cdot \mathrm{m}$ or less (16).

\section{Thin Ion-Implanted Laver of CVD Diamond}

The effect of carbon and nitrogen ion implantation on diamond's friction and wear properties was significant (Fig. 6(c)). Both carbon-ion-implanted diamond and nitrogen-ion-implanted diamond exhibited low coefficients of friction $(<0.1)$ and low wear rates (on the order of $10^{-6} \mathrm{~mm} / \mathrm{N} \cdot \mathrm{m}$ ), making them acceptable for solid lubrication applications $(15,16)$. Bombarding diamond films with carbon ions at $60 \mathrm{keV}$ or with nitrogen ions at $35 \mathrm{keV}$ produced a thin, superficial layer of amorphous, nondiamond carbon $(<1 \mu \mathrm{m}$ thick). This surface layer greatly reduced the coefficient of friction and the wear rate in ultrahigh vacuum to values that are acceptable for self-lubricating, wear-resistant applications of CVD diamond films.

Note that in dry nitrogen and in humid air (not shown) the coefficient of friction was less than 0.05 and the wear rate was on the order of $10^{-6} \mathrm{~mm}^{3} / \mathrm{N} \cdot \mathrm{m}(15,16)$. 

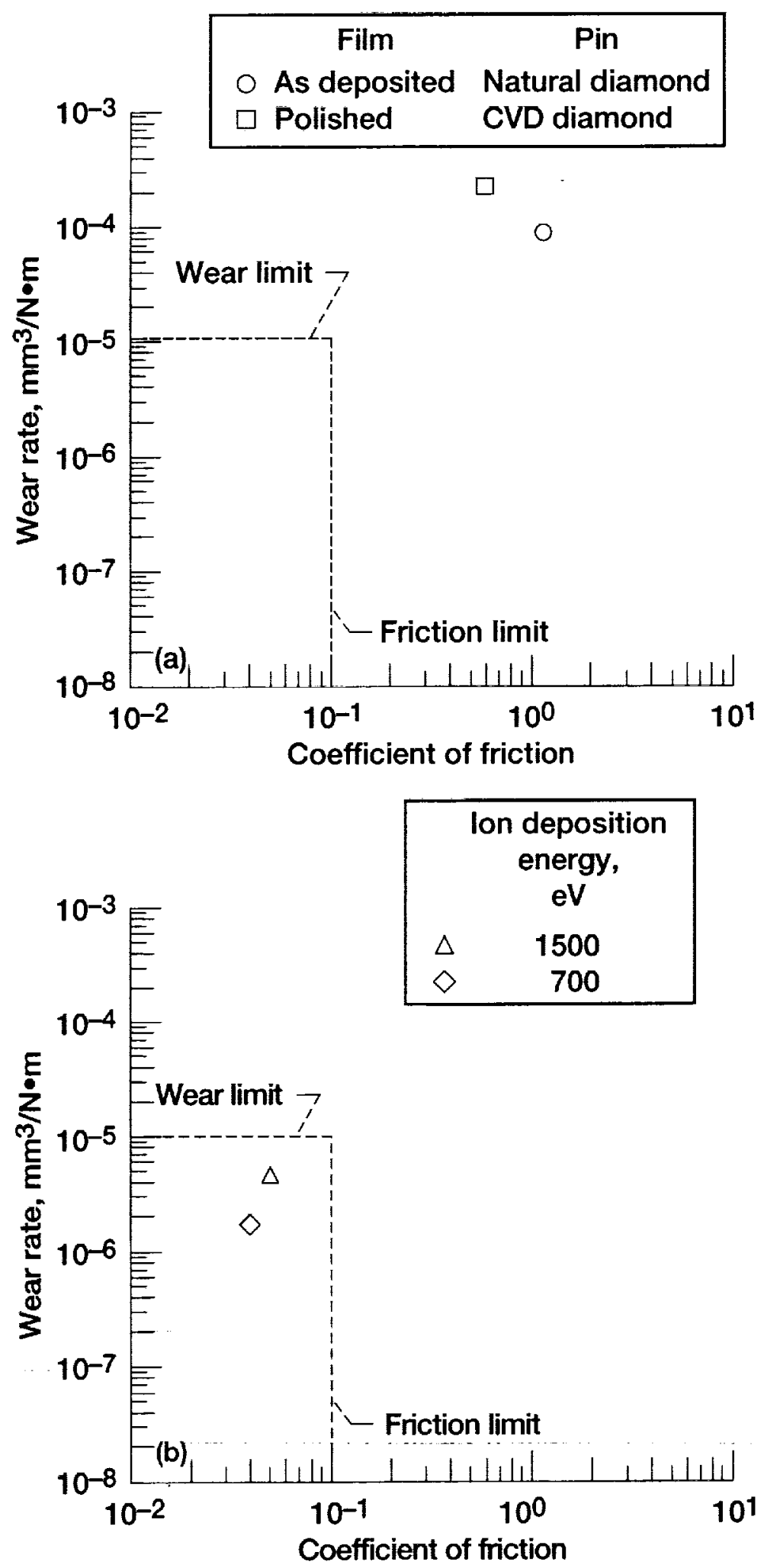

Figure 6.-Comparison of coefficient of friction and wear rate. (a) As-deposited diamond and polished diamond. (b) DLC films deposited on fine-grain diamond at 1500 and $700 \mathrm{eV}$. (c) Carbon-ion-implanted diamond and nitrogen-ion-implanted diamond. 


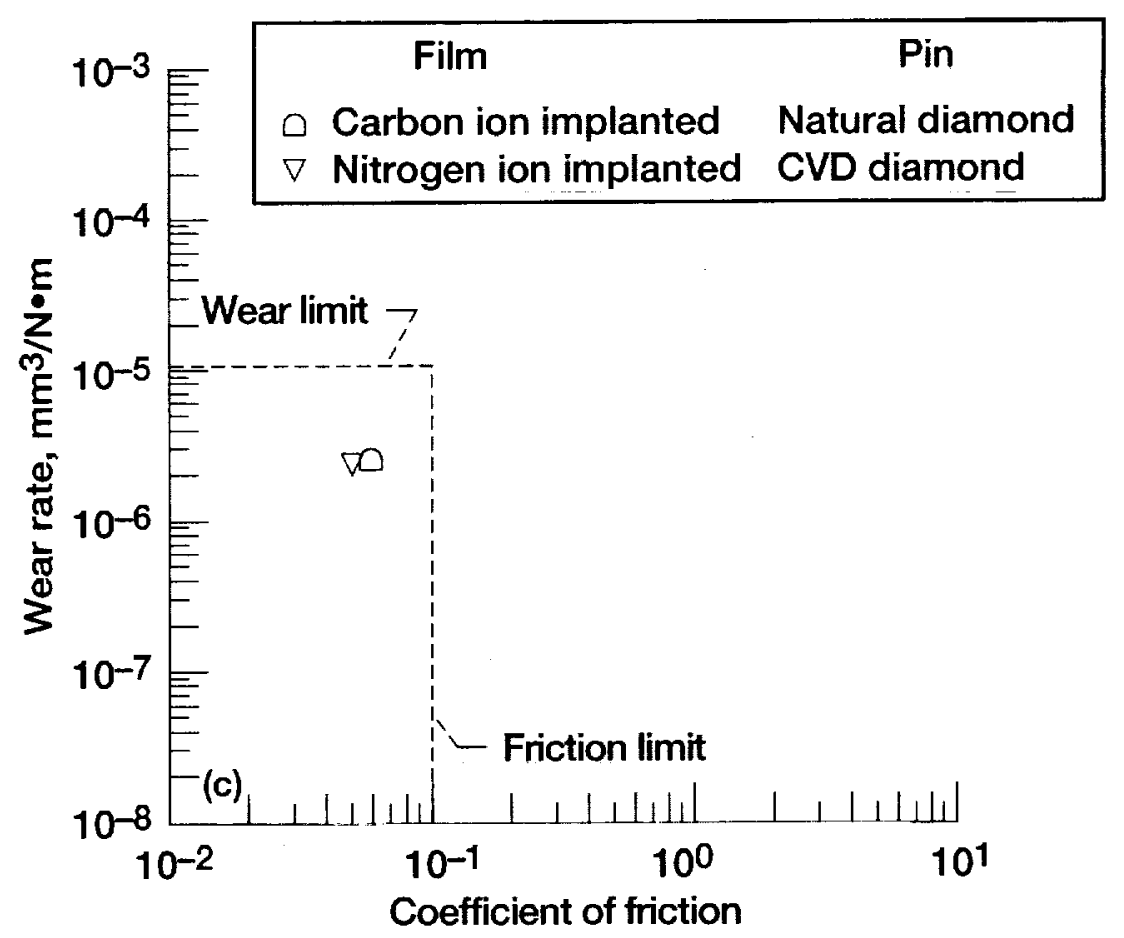

Figure 6.-Concluded.

\section{Selected Materials Couple}

Boron nitride is competing with diamond and silicon carbide in most applications, including frictionreducing coatings. Similar to diamond, a wide variety of synthesis methods are being used, and boron nitride can be grown in many phases. The cubic phase is the most desirable phase for tribological applications (17). Because cubic boron nitride (c-BN), which is chemically and thermally inert, is second only to diamond in hardness, many researchers believe that $\mathrm{c}-\mathrm{BN}$ films offer great opportunities for wear parts, cutting tool inserts, rotary tools, and dies. The c-BN films are especially valuable for protective coatings on surfaces that come into contact with iron-based materials, where diamond cannot be used because of its high chemical wear due to its aggressive reaction with iron. Therefore, an investigation was conducted to examine the friction of c-BN in contact with diamond in ultrahigh vacuum. Reference experiments were also conducted in dry nitrogen and in humid air. The c-BN films (approx. $0.5 \mu \mathrm{m}$ thick) were synthesized by magnetically enhanced plasma ion plating and formed on silicon $\{100\}$ wafer substrates (18).

Figure 7 shows the low average coefficients of friction in ultrahigh vacuum for as-deposited c-BN films in sliding contact with CVD diamond pins as a function of the number of passes. This materials combination provided an effective self-lubricating, wear-resistant couple in ultrahigh vacuum at low numbers of passes. However, at approximately 1400 passes the sliding action caused the c-BN film to break down, whereupon the coefficient of friction rapidly increased (Fig. 7). The wear rate of this particular c-BN film sliding against CVD diamond pin was on the order of $10^{-6} \mathrm{~mm}^{3} / \mathrm{N} \cdot \mathrm{m}$, but the wear rate of the CVD diamond pin was much lower. 


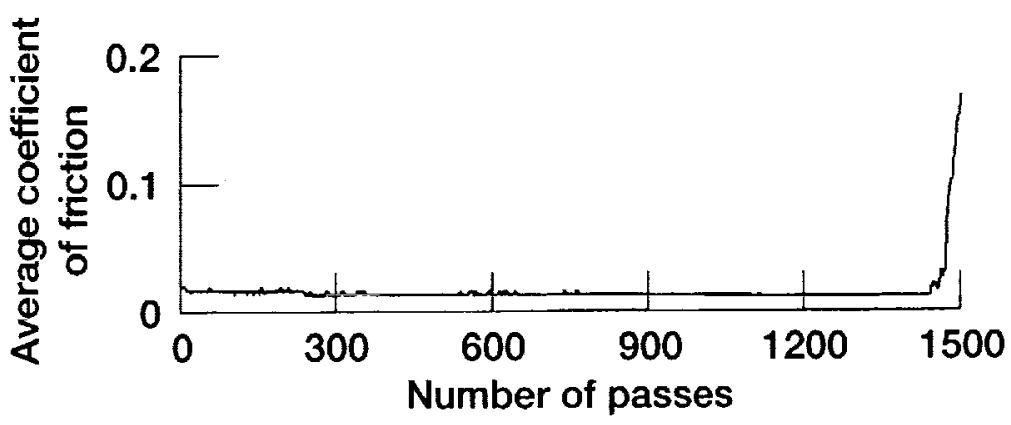

Figure 7.-Coefficient of friction for C-BN films in sliding contact with CVD diamond pins in ultrahigh vacuum.

Note that in dry nitrogen and in humid air (not shown) the coefficient of friction remained constant for a long period without breakdown even at 100000 passes (16). The endurance life of c-BN films was greater in dry nitrogen and in humid air than in ultrahigh vacuum by a factor of 60 or higher.

\section{Conclusions}

Three studies on the surface design, surface engineering, and tribology of chemical-vapor-deposited (CVD) diamond have shown that its normally high friction and wear in ultrahigh vacuum can be significantly reduced. The main criteria for judging the performance of diamond films to be an effective wear-resistant, self-lubricating material were coefficient of friction and wear rate, which had to be less than 0.1 and on the order of $10^{-6} \mathrm{~mm}^{3} / \mathrm{N} \cdot \mathrm{m}$, respectively. The following conclusions were drawn from the results of these studies:

1. The presence of a thin film ( $<1 \mu \mathrm{m}$ thick) of amorphous, nondiamond carbon (hydrogenated carbon, also called diamondlike carbon or DLC) on CVD diamond greatly decreased the coefficient of friction and the wear rate. Therefore, a thin DLC film on CVD diamond can be an effective wear-resistant, lubricating coating in ultrahigh vacuum.

2. The presence of an amorphous, nondiamond carbon surface layer formed on the diamond by ion implantation significantly reduced the coefficient of friction and the wear rate in ultrahigh vacuum to values that are acceptable for effective self-lubricating, wear-resistant applications of CVD diamond films.

3. CVD diamond in contact with cubic boron nitride exhibited low coefficients of friction in ultrahigh vacuum. Therefore, this materials combination can provide an effective self-lubricating, wear-resistant couple in ultrahigh vacuum.

\section{References}

1. H.P. Jost, "Tribology-Origin and Future," Wear, 136 (1990), 1-17.

2. K. Miyoshi, "Superhard Coatings Approaches to Tribology: Properties and Applications of CVD Diamond, DLC, and c-BN" (Paper presented at Wear and Superhard Coatings 1998, Tampa, Florida, March 2-4, 1998), 1-15. 
3. M.T. Dugger, D.E. Peebles, and L.E. Pope, "Counterface Material and Ambient Atmosphere: Role in the Tribological Performance of Diamond Films," Surface Science Investigations in Tribology: Experimental Approaches, eds. Y.-W. Chung, A.M. Homola, and G.B. Street (Washington, DC: American Chemical Society (ACS Symposium Series 485), 1992), 72-102.

4. M.N. Gardos, "Tribology and Wear Behavior of Diamond," Synthetic Diamond: Emerging CVD Science and Technology, eds. K.E. Spear and J.P. Dismukes (New York, NY: John Wiley \& Sons, Inc., 1994), 419-502.

5. I.P. Hayward, I.L. Singer, and L.W. Seitzmann, "The Tribological Behaviour of Diamond Coatings," Proceedings of the Second International Conference on the New Diamond Science and Technology (Pittsburgh, PA: Materials Research Society, 1991), 785-789.

6. F.P. Bowden and D. Tabor, The Friction and Lubrication of Solids (Oxford, England: Clarendon Press, 1958).

7. D. Tabor, "Adhesion and Friction," Properties of Diamond, ed. J.E. Field (New York, NY: Academic Press, 1979) $325-350$.

8. K. Holmberg and A. Matthews, Coatings Tribology: Properties, Techniques, and Applications in Surface Engineering (Amsterdam, The Netherlands: Elsevier, 1994) (Tribology Series 28).

9. I.L. Singer, "Solid Lubrication Processes," Fundamental of Friction: Microscopic and Macroscopic Processes, Proceedings of NATO Advanced Study Institute, eds. I.L. Singer and H.M. Pollock (Dordrecht, Netherlands: Kluwer Academic Publishers, 1992) 237-261.

10. I.M. Hutchings, Tribology: Friction and Wear of Engineering Materials (Boca Raton, FL: CRC Press, 1992).

11. K. Miyoshi, "Adhesion in Ceramics and Magnetic Media," Proceedings of the Fifth Intermational Congress on Tribology, ed. K. Holmberg (Espoo, Finland: The Finnish Society for Tribology, 1989) 228-233.

12. K. Miyoshi, "Adhesion, Friction, and Wear Behavior of Clean Metal-Ceramic Couples," Proceedings of the International Tribology Conference, Yokohama 1995, Vol. III (Tokyo, Japan: Japanese Society of Tribologists, 1995) 1853-1858.

13. K. Miyoshi, R.L.C. Wu, A. Garscadden, P.N. Barnes, and H.E. Jackson, "Friction and Wear of Plasma-Deposited Diamond Films," J. Appl. Phys., 74 (7) (1993), 4446-4454.

14. K. Miyoshi, "Wear-Resistant, Self-Lubricating Surfaces of Diamond Coatings," Proceedings of the Third International Conference on the Applications of Diamond Films and Related Materials (NIST Special Publications Issue 885,1995$), 493-500$.

15. K. Miyoshi, "Lubrication by Diamond and Diamondlike Carbon Coatings," J. Tribology, 120 (1998), 379-384.

16. K. Miyoshi, M. Murakawa, S. Watanabe, S. Takeuchi, S. Miyake, and R.L.C. Wu, "CVD Diamond, DLC, and c-BN Coatings for Solid Film Lubrication," Tribology Letters, 5 (1998), 123-129.

17. J.J. Pouch and S.A. Alterovitz, eds., Synthesis and Properties of Boron Nitride, Materials Science Forum, vols. 54 and 55 (Zurich, Switzerland: Trans Tech Publications, 1990).

18. S. Watanabe, D.R. Wheeler, P.S. Abel, K.W. Street, K. Miyoshi, M. Murakawa, and S. Miyake, "Surface Chemistry, Microstructure, and Tribological Properties of Cubic Boron Nitride Films" (NASA Technical Memorandum 113163, 1998). 


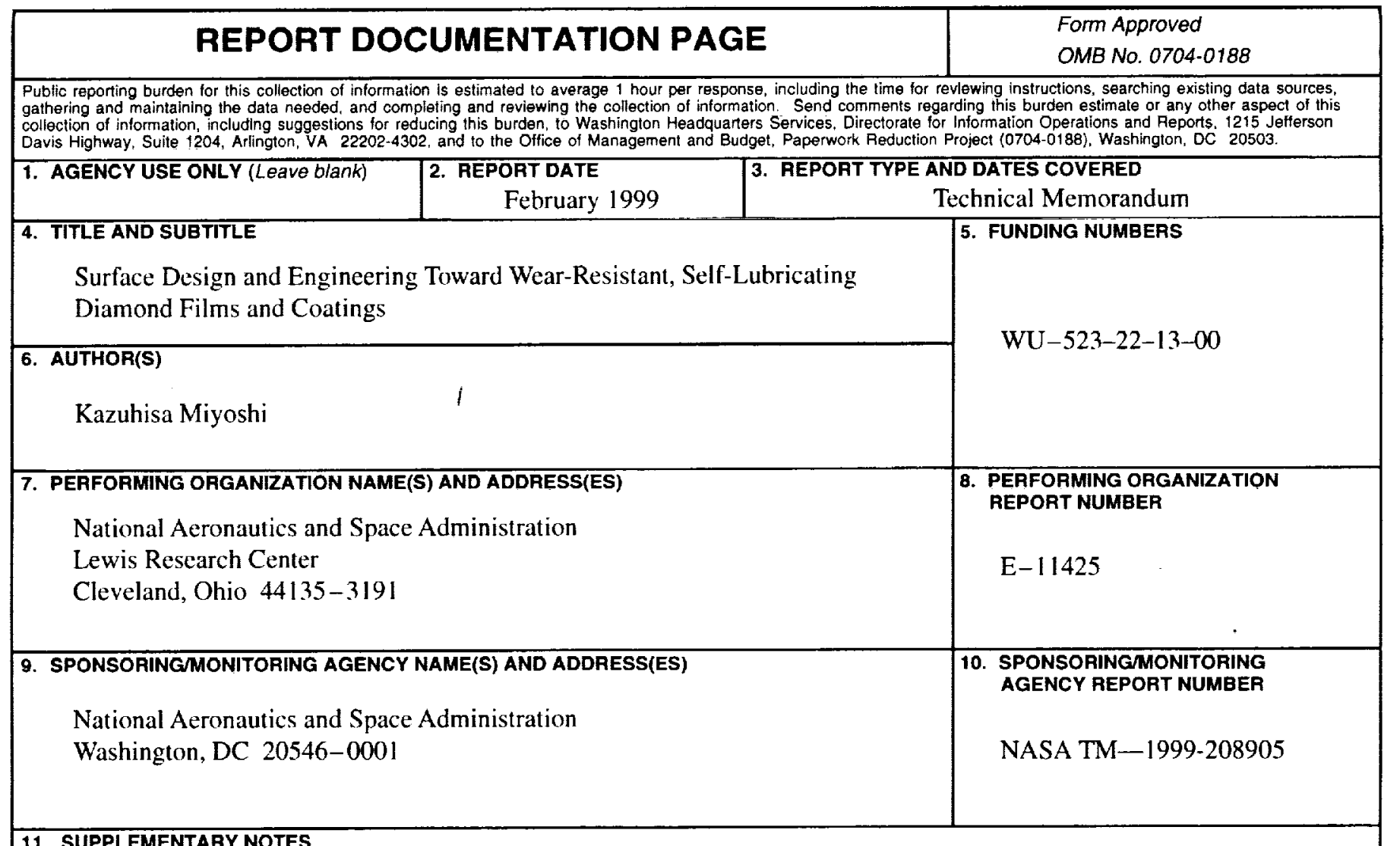

\section{SUPPLEMENTARY NOTES}

Prepared for the 128th Annual Meeting \& Exhibition sponsored by The Minerals, Metals \& Materials Society, San Diego, California, February 28-March 4, 1999. Responsible person, Kazuhisa Miyoshi, organization code 5140, (216) 433-6078.

12a. DISTRIBUTION/AVAILABILITY STATEMENT

12b. DISTRIBUTION CODE

Unclassified - Unlimited

Subject Category: 27

Distribution: Nonstandard

This publication is available from the NASA Center for AeroSpace Information, (301) 621-0390.

13. ABSTRACT (Maximum 200 words)

The tribolngical properties of chemical-vapor-deposited (CVD) diamond films vary with the environment, possessing a Jekyll-andHyde character. CVD diamond has low coefficient of friction and high wear resistance in air but high coefficient of friction and low wear resistance in vacuum. Improving the tribological functionality of materials (such as achieving low friction and good wear resistance) was an aim of this investigation. Three studies on the surface design, surface engineering, and tribology of CVD diamond have shown that its friction and wear are significantly reduced in ultrahigh vacuum. The main criteria for judging whether diamond films are an effective wear-resistant, self-lubricating material were coefficient of friction and wear rate, which must be less than 0.1 and on the order of $10^{-6} \mathrm{~mm}^{3} / \mathrm{N} \cdot \mathrm{m}$, respectively. In the first study the presence of a thin film $(<1 \mathrm{~mm}$ thick $)$ of amorphous, nondiamond carbon (hydrogenated carbon, also called diamondlike carbon or DLC) on CVD diamond greatly decreased the coefficient of friction and the wear rate. Therefore, a thin DLC film on CVD diamond can be an effective wear-resistant, lubricating coating in ultrahigh vacuum. In the second study the presence of an amorphous, nondiamond carbon surface layer formed on CVD diamond by ion implantation significantly reduced the coefficient of friction and the wear rate in ultrahigh vacuum. Therefore, such surface layers are acceptable for effective self-lubricating, wear-resistant applications of CVD diamond. In the third study CVD diamond in contact with cubic boron nitride exhibited low coefficient of friction in ultrahigh vacuum. Therefore, this materials combination can provide an effective self-lubricating. wear-resistant couple in ultrahigh vacuum.

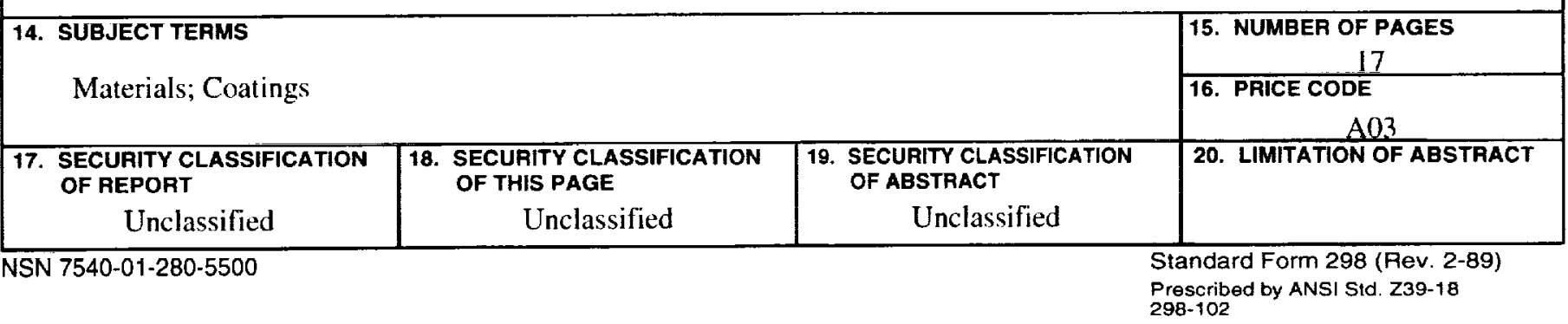

